\title{
The Effect of Crack Width on Chloride-Induced Corrosion of Steel in Concrete
}

\author{
Weiwei Li, Weiqing Liu, and Shuguang Wang \\ College of Civil Engineering, Nanjing Tech University, Nanjing 211816, China \\ Correspondence should be addressed to Weiqing Liu; wqliu@njtech.edu.cn
}

Received 22 March 2017; Accepted 15 June 2017; Published 19 July 2017

Academic Editor: Antonino Squillace

Copyright (C) 2017 Weiwei Li et al. This is an open access article distributed under the Creative Commons Attribution License, which permits unrestricted use, distribution, and reproduction in any medium, provided the original work is properly cited.

\begin{abstract}
When subjected to loading or thermal shrinkage, reinforced concrete structures usually behave in a cracking state, which raises the risk of bar corrosion from the working environment. The influence of cover cracking on chloride-induced corrosion was experimentally investigated through a 654-day laboratory test on cracked reinforced concrete specimens exposed to chloride solution. The concrete specimens have a dimension of $100 \mathrm{~mm} \times 100 \mathrm{~mm} \times 400 \mathrm{~mm}$ and a single prefabricated crack at the midspan. When the percentage concentration of chloride ion $(0.6 \%, 1.2 \%, 2.1 \%, 3.0 \%$, and $6.0 \%)$ and crack width (uncracked, $0.2,0.3,0.4$, and $0.5 \mathrm{~mm}$ ) are taken as variables, the experimental results showed that the corrosion rates for cracked specimens increased with increasing percentage concentration of chloride and increasing crack width. This study also showed the interrelationship between crack width and percentage concentration of chloride on the corrosion rate. In addition, an empirical model, incorporating the influence of the cover cracking and chloride concentration, was developed to predict the corrosion rate. This model allows the prediction of the maximum allowable $w_{\mathrm{cr}}$ based on the given percentage concentration of chloride in the exposure condition.
\end{abstract}

\section{Introduction}

Uncracked concrete covering rebar provides a high $\mathrm{pH}$ value and physical barrier [1] in concrete to protect the rebars from the ingress of aggressive substances, such as chloride or sulfate, in a marine environment. Usually, improving the cover quality (such as reducing the water-to-binder ratio or using supplementary cementitious materials) raises the mechanical performance and durability of concrete. In practice, however, most concrete structures subjected to mechanical load or thermal shrinkage behave in a cracking state $[2,3]$, leading to a higher risk of corrosion in reinforced concrete. The appearance of cracks allows a more rapid diffusion of aggressive ions and an earlier initiation of corrosion of reinforcement, especially when chloride exists in the service environment [4-6]. Therefore, the investigations on the corrosion mechanism and corrosion rate of rebars in cracked reinforced concrete subjected chloride environment are essential and have been the topic for numerous researches in decades.

In literature, the effect of cracks on the initiation and development of chloride-induced corrosion in cracked reinforced concrete elements has been widely studied by experiments under accelerated conditions. In experiments, accelerated corrosion is usually achieved by using one of several techniques, including the use of impressed current, admixed chlorides, chloride solutions, and the use of simulated concrete pore solutions. Ohno et al. [7] investigated the influence of a signal flexural crack and multiple flexural cracks on rebar corrosion. The results suggested that, in concrete with multiple cracks, the corrosion rate was much higher at certain one of the cracks than the others. Using concrete samples with manual cracks, Arya and Ofori-Darko [8] further indicated that samples with a small number of cracks had a lower corrosion rate than samples with a large number of cracks. Some influential parameters, such as the laboratory methods of making the cracks (precast cracks or loading cracks), the tortuosity of the cracks, and/or depth and width of the cracks, were reported to have significant effects on the penetration of chloride ion [9]. Within these parameters, the width of the cracks is the most influential one. $\operatorname{Li}[10,11]$ found that chloride ions permeated the surface of rebar more rapidly when the crack width was larger than $0.1 \mathrm{~mm}$, which allowed an earlier initiation of corrosion of the 


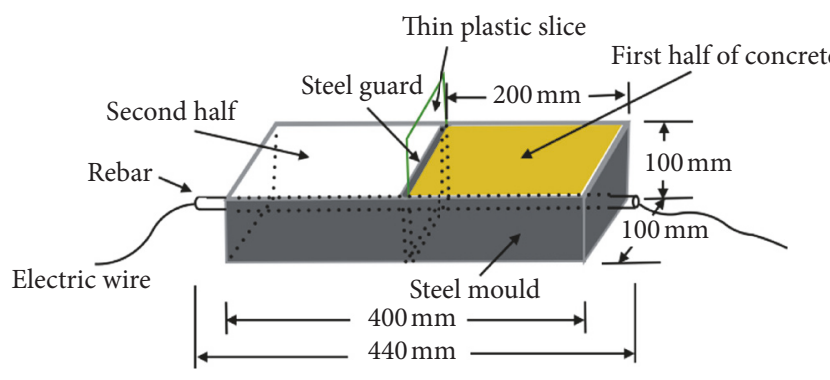

(a) Pouring the specimen in two parts

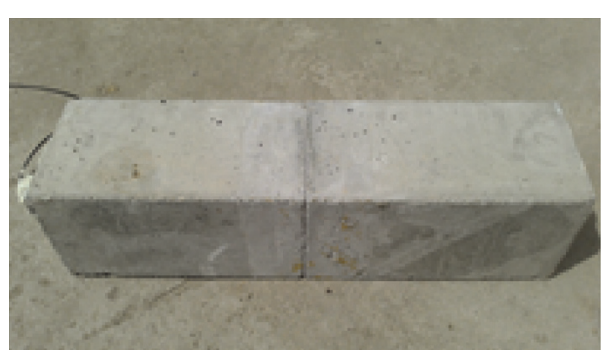

(b) Test specimen with transverse crack

FIGURE 1: Schematic of the cracked concrete.

TABLE 1: Mixture proportions of prism concrete.

\begin{tabular}{cccccccc}
\hline W/B & & & \multicolumn{2}{c}{ Unit weight $\left(\mathrm{kg} / \mathrm{m}^{3}\right)$} & Coarse aggregate & Super plasticizer \\
& Water & Cement & Fly ash & Slag & Fine aggregate & C & C \\
\hline 0.43 & 160 & 250 & 55 & 65 & 770 & 1030 & 3.97 \\
\hline
\end{tabular}

TABLE 2: Elemental composition of the rebar.

\begin{tabular}{lccccccccc}
\hline Elements & $\mathrm{Fe}$ & $\mathrm{C}$ & $\mathrm{Si}$ & $\mathrm{Mn}$ & $\mathrm{P}$ & $\mathrm{Al}$ & $\mathrm{Cr}$ & $\mathrm{Ni}$ & $\mathrm{S}$ \\
\hline $\mathrm{wt} \%$ & 99.67 & 0.038 & 0.03 & 0.21 & 0.012 & 0.01 & 0.01 & 0.01 & 0.01 \\
\hline
\end{tabular}

reinforcement. Schiessl and Raupach [12] suggested that both the width and depth of the crack were related to the risk of initiation of reinforcement corrosion, whereas the width of the crack had a more remarkable influence on the corrosion initiation. Montes et al. [13] and Ohno et al. [14] found that the width of the crack influenced the corrosion rate up to $0.5 \mathrm{~mm}$ and that, in cracked concrete elements, the corrosion rate was 10 times higher than in uncracked elements. Through a long-time exposure experiment for beam samples, however, François and Arliguie [15] and Vidal et al. [16] concluded that the appearance of transverse cracks and the crack width (no more than $0.5 \mathrm{~mm}$ ) had a minimal effect on the corrosion process of reinforced concrete elements. Jaffer and Hansson [17] found that corrosion only occurred on the rebar surface in the vicinity of the transverse cracks in cracked reinforced concretes when exposed to chlorides and that the uncracked regions far from the transverse cracks were usually passive. Though considerable research has been carried out on the accelerating rebar corrosion, the influence of cracking on corrosion rate can hardly be quantitatively described. Furthermore, more efforts are prerequisite to reveal the combination influences of both the width of crack and the chloride concentration.

This paper presents an experimental investigation on the corrosion mechanism and rate of transverse-cracked reinforced concrete beam samples immersed in $\mathrm{NaCl}$ solution. A long term experiment of 654 days was carried out and the crack width and concentration of chloride ions were taken as the influential variables. Based on the potential and polarization tests using an electrochemical station, the preliminary experimental results of the impact of crack width and concentration of chloride ions on the corrosion rate are reported herein.

\section{Experimental Investigation}

2.1. Specimens and Materials. The tests were carried out on the prism concrete specimens with dimensions of $100 \times 100$ $\times 400 \mathrm{~mm}^{3}$ and the transverse cracks were prefabricated at the middle span of the test specimens, as shown in Figure 1. Plain round bars were centrally embedded in concrete with a clear thickness of concrete cover of $40 \mathrm{~mm}$. Concrete with the target design compressive strength of $35 \mathrm{MPa}$, that is, C35, was prepared for the tests and the mix proportions are shown in Table 1. The compressive strength of concrete was tested on the cubic specimens (with side length of $150 \mathrm{~mm}$ ) at the age of 28 days and the average compressive strength is $37.55 \mathrm{MPa}$.

Plane round reinforcing bars with yielding strength of $235 \mathrm{MPa}$, that is, Q235, were used as working electrodes for the specimens and the element component of rebar is shown in Table 2 . The plain round rebars are prepared with a diameter of $20 \mathrm{~mm}$ and a length of $440 \mathrm{~mm}$. The coating of rebar was firstly removed through polishing by grinding machine and sandpaper. Both ends of the rebar (about $20 \mathrm{~mm}$ ) were then coated with epoxy. As a result, the length of the corrosion region of the working electrode is $400 \mathrm{~mm}$ and the exposed surface area approximates $251.2 \mathrm{~cm}^{2}$.

2.2. Cracking the Specimens. Based on literature [18], improved fabrication process has been developed to prefabricate the cracked concrete specimens, which is schematically shown in Figure 1. To prefabricate a transverse crack in the midspan of the specimens, each specimen was cast in two parts. Firstly, a steel plate with a size of $100 \mathrm{~mm} \times 100 \mathrm{~mm}$ was fixed at the midst of the steel mold. A thin plastic slice with size of $150 \mathrm{~mm} \times 100 \mathrm{~mm}$ was placed beside the steel plate and then attached to the steel plate. Holes of $20 \mathrm{~mm}$ 


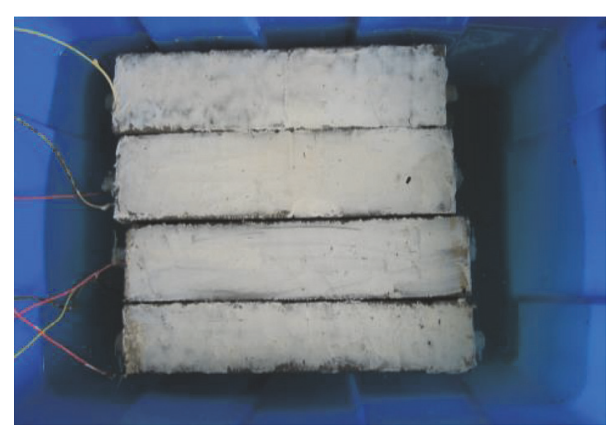

FIGURE 2: Experiment setup for accelerated chloride penetration test.

diameter were prefabricated at the center of the side plates of mold, steel plates, and plastic slices. The plain round rebars were longitudinally placed at the center of the mold through the holes at the side plates of mold, steel plates, and plastic slices. Secondly, the first half of the mold was filled with the prepared concrete and vibrated by the vibrating table. After curing in the steam conditions for 7 hours, the steel guard fixed at the midspan was removed. Thirdly, the second half of the molds was filled with the prepared concrete which had the same material and mechanical properties of the concrete for the first half. After another 7 hours of curing, the specimens were demolded from the molds and then thin plastic slice was removed from the specimens. At last, prism specimens were water-cured for 7 days in the laboratory. The variation of the width of the transverse cracks was performed by using the thin plastic slice with different thicknesses. When no thin plastic slice was used, uncracked specimens, that is, crack width $0 \mathrm{~mm}$, were prepared. In summary, the nominal widths of transverse cracks were $0 \mathrm{~mm}, 0.2 \mathrm{~mm}$, $0.3 \mathrm{~mm}, 0.4 \mathrm{~mm}$, and $0.5 \mathrm{~mm}$.

2.3. Rapid Ion Penetration Test. A series of rapid ion penetration tests were conducted with the experiment setup as shown in Figure 2. For each specimen, four side surfaces of the specimen were coated with epoxy, and the other two surfaces, which are on opposite sides of the sample, were left uncovered. All specimens were firstly submerged in clear water for 24 hours before the experiment and then they were immersed in the $\mathrm{NaCl}$ solution. There are 25 working conditions designed for the experiment, with two test variables including the concentration of the chloride ion and the width of prefabricated cracks. The concentrations of the chloride ion $\left(\mathrm{Cl}^{-}\right)$are $0.6 \%, 1.2 \%, 2.1 \%, 3.0 \%$, and $6.0 \%$ by weight of the solution, respectively. And the crack widths of prefabricated cracks are $0,0.2,0.3,0.4$, and $0.5 \mathrm{~mm}$, respectively.

\section{Electrochemical Measurement Methods}

Open circuit corrosion potential and polarization tests were carried out in this research. A three-electrode system was utilized to monitor the test data, in which the rebar embedded in concrete was taken as the working electrode, and a saturated calomel electrode (SCE) and a platinum electrode

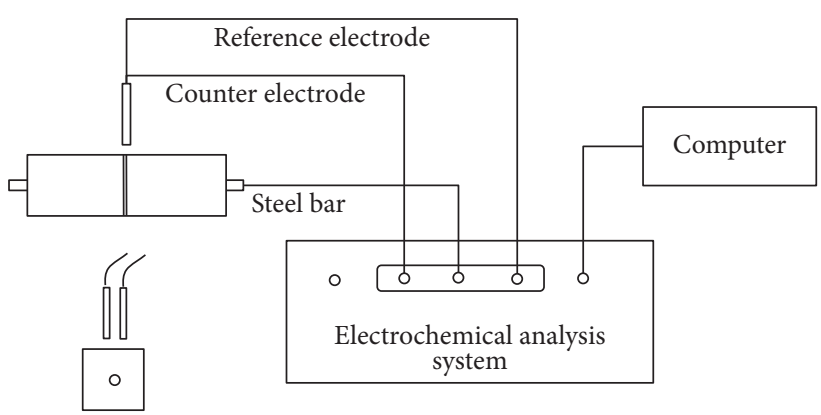

FIGURE 3: Electrochemical analysis system.

were used as the reference electrode and the counterelectrode, respectively. The reference electrode and the platinum electrode were placed on the surface of the concrete cover, spaced $2 \mathrm{~cm}$ apart and positioned close to the crack. The electrochemical analysis system is shown in Figure 3.

Open circuit corrosion potential measurements were conducted on the first day after the specimens were immersed in the chloride solution. Afterwards, they were conducted 51 times on the specimens during the experimental period.

Polarization tests were also conducted on the first day after the starting of the experiments and then were conducted 51 times by sweeping the potential at a rate of $1 \mathrm{mV} / \mathrm{s}$ over a potential range of $\pm 40 \mathrm{mV}$ versus the corrosion potential. The change of potential, $\Delta E$, was given by the difference of the open circuit potential and the corrosion potential, as shown in

$$
\Delta E=E-E_{\text {corr }},
$$

where $E$ is the potential conducted and $E_{\text {corr }}$ is the corrosion potential measured in open circuit corrosion potential test.

Since the current density was proportional to the current $I_{c}$ recorded by electrochemical workstation, the current density $i$ can be given by

$$
i=\frac{I_{c}}{A},
$$

where $A$ is the corroding area of rebar $\left(251.2 \mathrm{~cm}^{2}\right.$ in this study).

The current density $i$, the change of potential $\Delta E$, and the corrosion current density $i_{\text {corr }}$ are corelated, and the corrosion current density $\left(i_{\text {corr }}\right)$ can be given by

$$
i=i_{\text {corr }}\left[\exp \left(\frac{\Delta E}{\beta_{a}}\right)-\exp \left(-\frac{\Delta E}{\beta_{c}}\right)\right]
$$

where $i_{\text {corr }}, \beta_{a}$, and $\beta_{c}$ can be calculated from the $i-\Delta E$ plot [19].

\section{Results and Discussions}

The results of the corrosion rate and the open circuit corrosion potential were collected for 654 days (nearly 24 months) at the exposure condition. As a result, there is adequate tested data to perform statistical analyses. The value of each point in the time-varying curve is the average value of the replicated specimens under the same experience condition. 
For the figures in which elapsed time is taken as horizontal axis, "Day zero" means the day when the specimens were just exposed to the experiment environment. Measurements were taken 6 hours after the specimens were immersed in the respective chloride solutions. "Average corrosion" refers to the arithmetic mean value of the measured corrosion rates from day 96 to day 654 . In this study, the arithmetic mean value of measured corrosion rate during the plateau phase (between days 96 and 654) was adopted to make the empirical equation more representative, with the variable of time excluded. In this case, the seasonal weather changed from summer to winter, the maximum temperature was approximately $27.8^{\circ} \mathrm{C}$, and the minimum temperature was approximately $7.5^{\circ} \mathrm{C}$.

4.1. The Time-Developed Corrosion Rate. The recorded corrosion current density, derived from the polarization measurements, is plotted with respect to the elapsed time as shown in Figure 4. The results show that the uncracked specimens had low corrosion current densities, whereas the cracked specimens had much higher ones. This result indicates that the appearance of cracks in the concrete produced a significant increase in the corrosion rate. This reason is probably associated with the exposure of the rebar to the chloride solution without a concrete cover.

The results also show that an increasing crack width $\left(w_{\mathrm{cr}}\right)$ results in an increased corrosion rate (i.e., corrosion current density). It is found that the corrosion rates initially decreased with elapsed time within the first week of the experiments. This is mainly attributed to the decrease in temperature and the decrease in concentration of the dissolved oxygen, which sustained the corrosion process. After 13 weeks of exposure in the respective environments, the corrosion rate tended to decay and reach a steady-state value. When plotting the corrosion rate versus time, therefore, it can be seen in Figure 4 that $i_{\text {corr }}$ basically attained a constant value after 13 weeks.

In this study, the corrosion which produces a value of the corrosion rate greater than $0.1 \mu \mathrm{A} / \mathrm{cm}^{2}$ (meaning a corrosion depth rate of $1 \mu \mathrm{m} /$ year) is considered as active corrosion. From this point of view, all these cracked specimens exhibited an active state of corrosion during the latter part of the experiment period (654 days). For the uncracked specimens, however, most of them were kept passive in the solutions with a lower concentration of chloride except for the specimen in the $6.0 \%$ chloride solution.

The influence of the concentration of chloride on the corrosion rate is also investigated in the study. With increasing concentration of chloride in the solution, the results in Figure 4 show that the corrosion rate has been remarkably increased. In the presence of $0.6 \%$ chloride, the corrosion rate varied from 0.05 to $0.25 \mu \mathrm{A} / \mathrm{cm}^{2}$, as shown in Figure $4(\mathrm{a})$, whilst the corrosion rate was in the range of $0.35 \sim 1.0 \mu \mathrm{A} / \mathrm{cm}^{2}$ in the presence of $6.0 \%$ chloride, as shown in Figure 4(e). It should be noted that, during the long term exposures, for uncracked specimens, passivity rupture was detected at chloride concentrations greater than $3.0 \%$. This result means that $3.0 \%$ is the critical chloride concentration for uncracked specimens to produce active corrosion. Figure 4 shows that, in these solutions, the corrosion rate for cracked concrete was greater than $0.1 \mu \mathrm{A} / \mathrm{cm}^{2}$ for most exposure time points, except for the sample with a $0.2 \mathrm{~mm}$ crack exposed to the $0.6 \%$ chloride solution. Therefore, the threshold values of chloride concentration were also obtained in these experiments for cracked concrete. The result is simply that the minimum value of crack width, which is also called the critical crack width, is a function of the concentration of chloride.

\subsection{Effect of Crack Width and the Concentration of the Chlo-} ride Solution on the Corrosion Rate. As pointed in the above section, the corrosion rates would reach steady-state values after 13 weeks for specimens subjected to different chloride solution. Thus, the average corrosion rate for each group of specimens is taken as the mean value of corrosion rates from day 96 to day 654. Figure 5 presents the comparisons of the average corrosion rates for specimens at the same experiment condition (the same concentration of chloride solution) but with different crack widths. The maximum and minimum values of $i_{\text {corr }}$ were obtained from the following equations:

$$
\begin{aligned}
& i_{\text {corr,max }}=i_{\text {corr,average }}+\sigma, \\
& i_{\text {corr,min }}=i_{\text {corr,average }}-\sigma,
\end{aligned}
$$

where $i_{\text {corr,average }}$ is the mean value of corrosion rate and $\sigma$ is the standard deviation.

The results show that averaged corrosion rate generally increased with increasing crack width $\left(w_{\mathrm{cr}}\right)$ (in the order of uncracked $<0.2 \mathrm{~mm}<0.3 \mathrm{~mm}<0.4 \mathrm{~mm}<0.5 \mathrm{~mm}$ ). In addition, the same trend was noticed when the chloride concentration was the independent variable; that is, the average corrosion rate increased with increasing chloride concentration in the order of $0.6 \%<1.2 \%<2.1 \%<3.0 \%<$ $6.0 \%$.

The average corrosion rates of uncracked specimens in all solutions were less than $0.1 \mu \mathrm{A} / \mathrm{cm}^{2}$. However, for cracked specimens, the average corrosion rates were higher than $0.1 \mu \mathrm{A} / \mathrm{cm}^{2}$, except for the concrete specimens with $0.2 \mathrm{~mm}$ crack exposed to the $0.6 \%$ chloride solution. The results show that, for cracked concrete, both the crack width and the chloride concentration should be limited to decrease the corrosion rate. This investigation suggests that the limit of the crack width is $0.2 \mathrm{~mm}$, and the limit value of chloride concentration is less than $0.6 \%$. If these two requirements are not both satisfied, the corrosion rate might be more than $0.1 \mu \mathrm{A} / \mathrm{cm}^{2}$.

The correlations among crack width $\left(w_{\mathrm{cr}}\right)$, chloride concentration of solution, and corrosion rate will be established as follows.

The correlation between the average corrosion rate and the concentration of chloride solution is presented in Figure 6. The figure shows that, in an accelerated corrosion experiment, for a given crack width, the corrosion rate increases with the increasing concentration of chloride solution. Moreover, a high correlation degree can be found between the average corrosion rate and the concentration of chloride solution (Adj. $R$-Square generally $>0.75$ ) for a given crack width. In general, the trends between the corrosion rate 


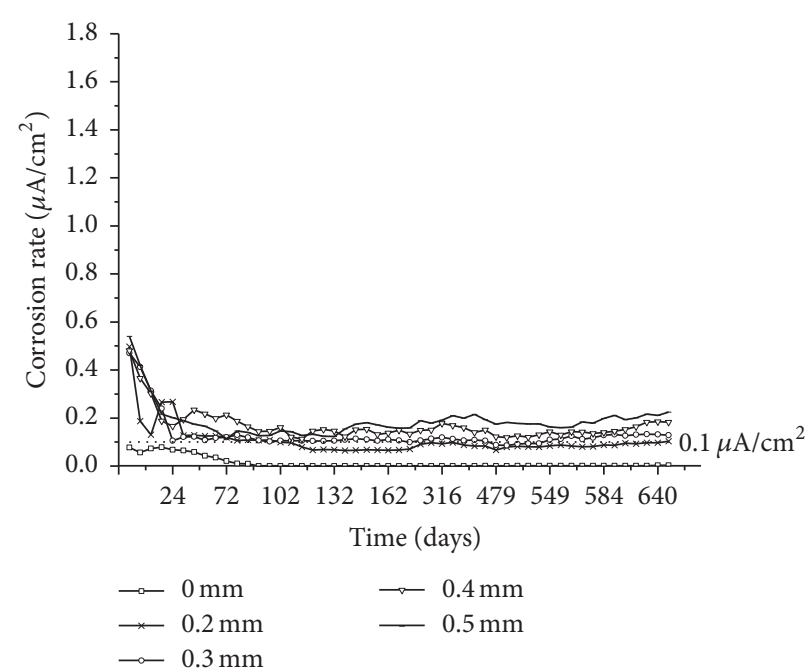

(a) $0.6 \%$ concentration of $\mathrm{Cl}^{-}$

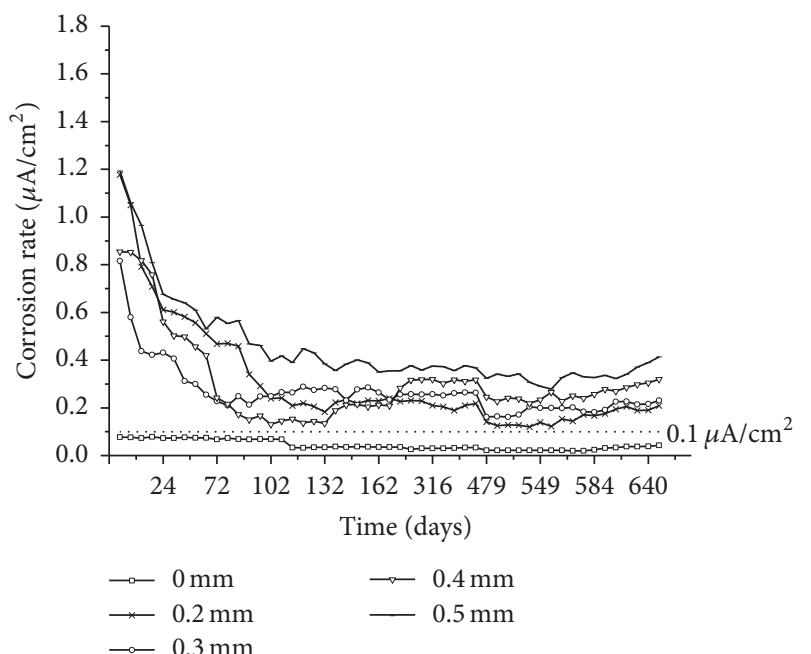

(c) $2.1 \%$ concentration of $\mathrm{Cl}^{-}$

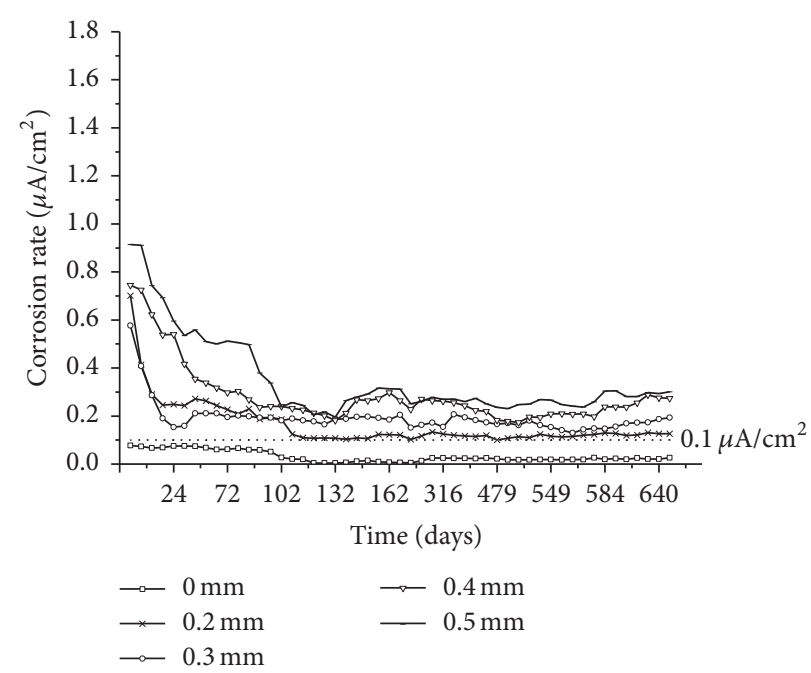

(b) $1.2 \%$ concentration of $\mathrm{Cl}^{-}$

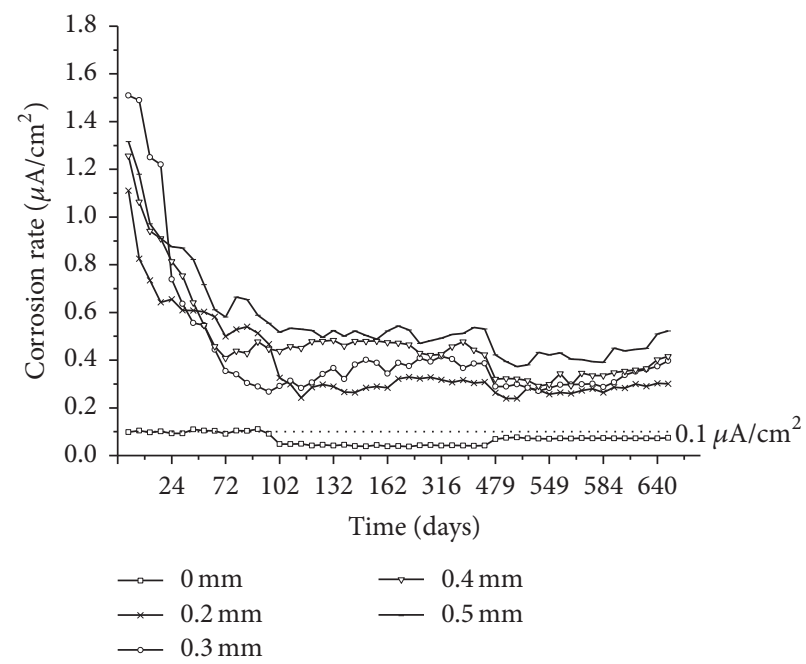

(d) $3.0 \%$ concentration of $\mathrm{Cl}^{-}$

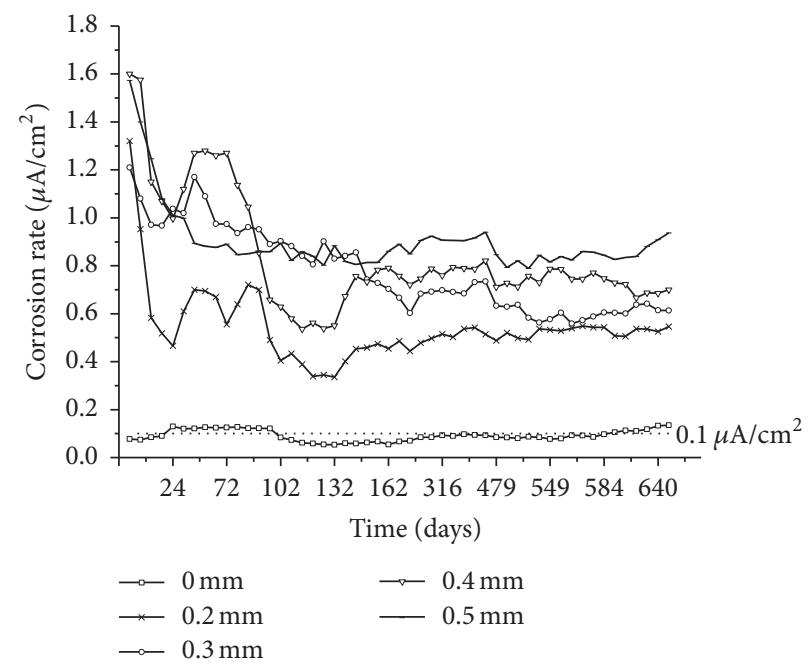

(e) $6 \%$ concentration of $\mathrm{Cl}^{-}$

FIGURE 4: Time-development of the corrosion rate in different concentrations of chloride. 


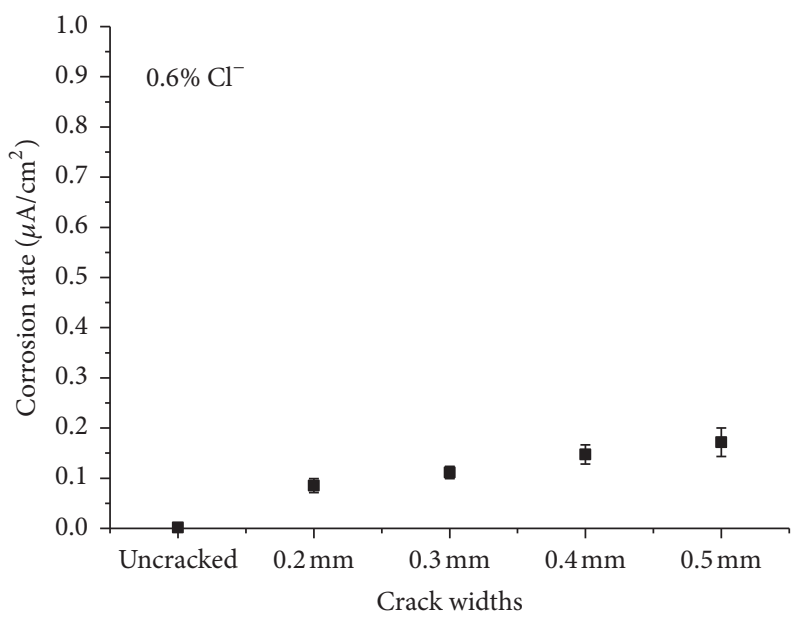

(a) $0.6 \%$ concentration of $\mathrm{Cl}^{-}$

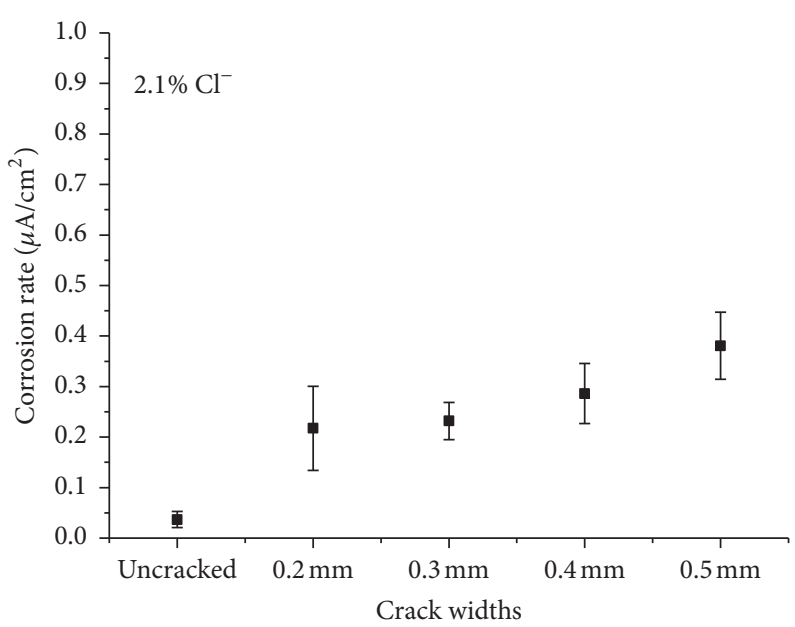

(c) $2.1 \%$ concentration of $\mathrm{Cl}^{-}$

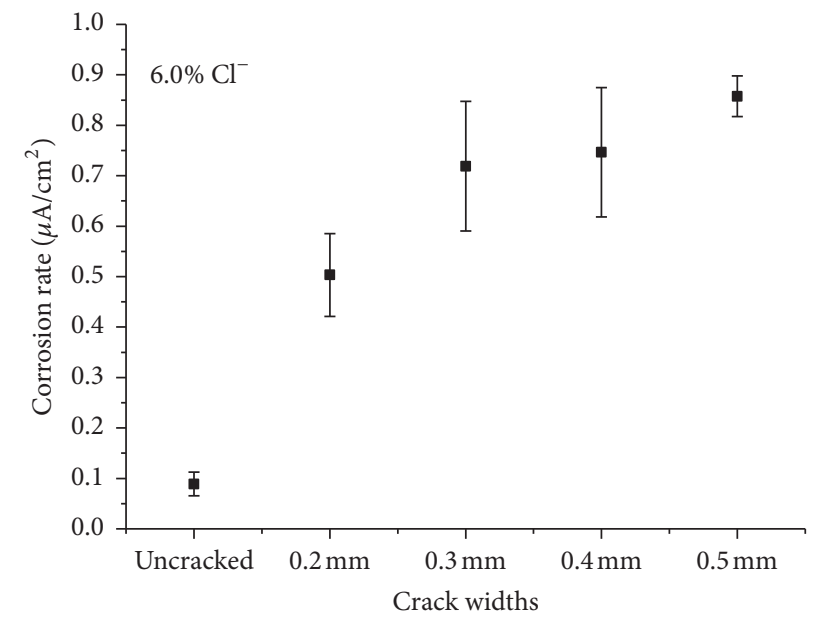

(e) $6 \%$ concentration of $\mathrm{Cl}^{-}$

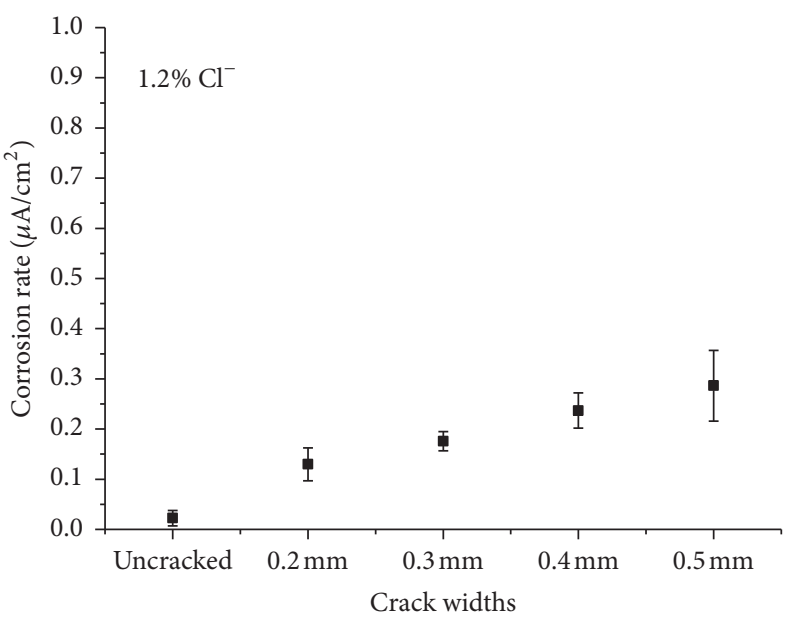

(b) $1.2 \%$ concentration of $\mathrm{Cl}^{-}$

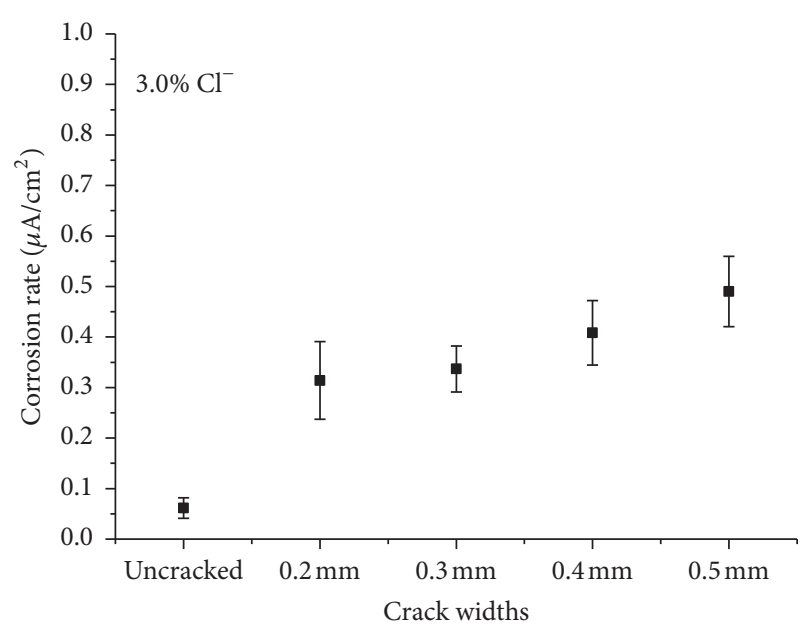

(d) $3.0 \%$ concentration of $\mathrm{Cl}^{-}$

Figure 5: Average corrosion rates in specimens. 


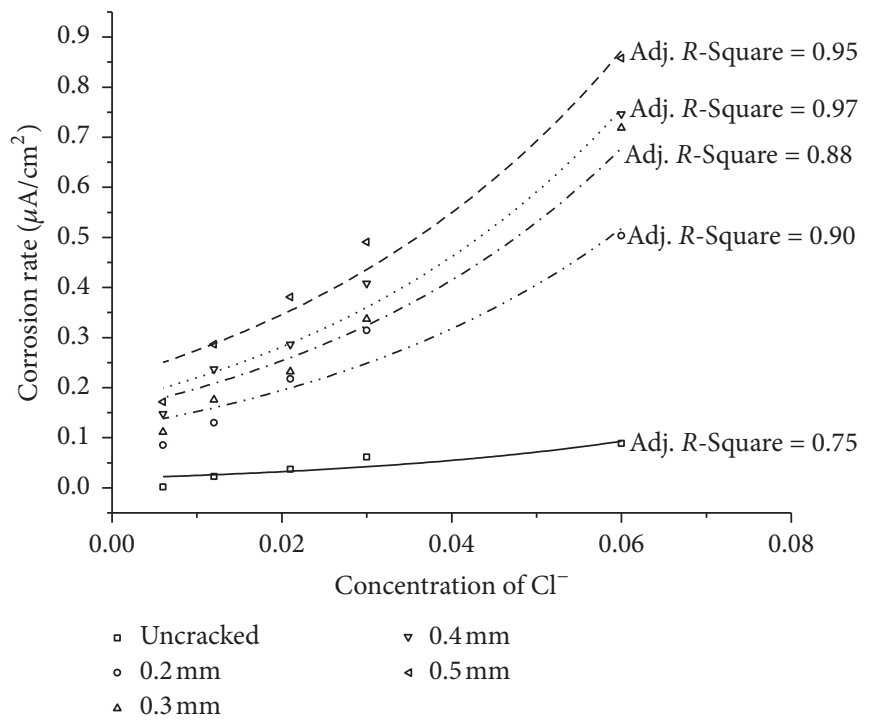

FIGURE 6: Average corrosion rates versus concentration of chloride solution.

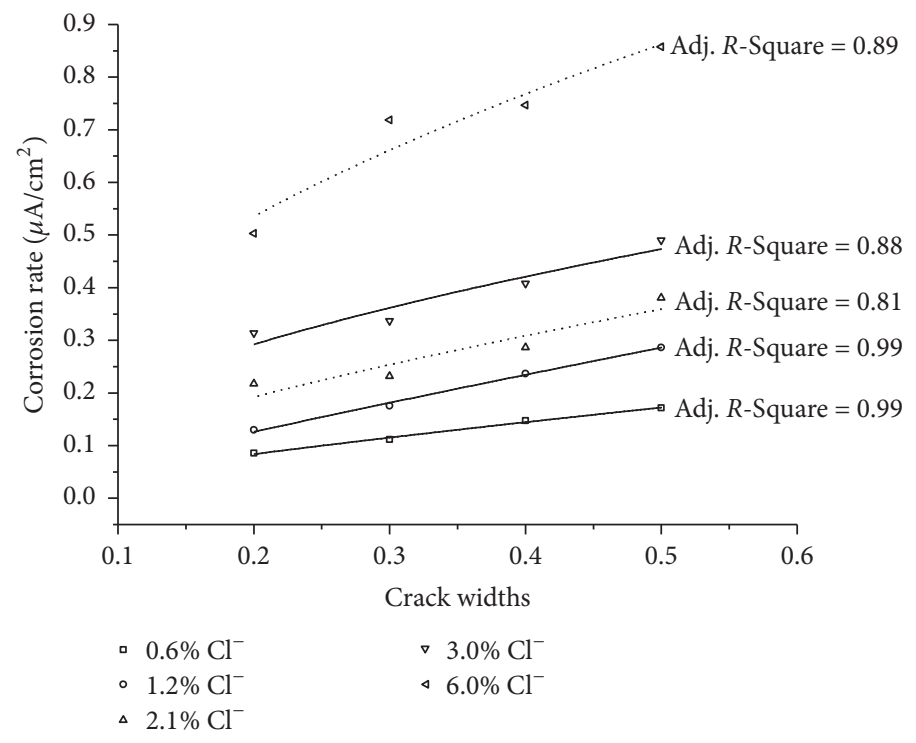

FIGURE 7: Average corrosion rate versus crack width (mm).

and the concentration of chloride solution shown in Figure 6 can be expressed as follows:

$$
i_{\text {corr }}=a e^{b D}\left[\mu \mathrm{A} / \mathrm{cm}^{2}\right],
$$

where $a\left(\mu \mathrm{A} / \mathrm{cm}^{2}\right)$ and $b(-)$, presented in Table 3, are coefficients depending on crack width and $D$ is the concentration of $\mathrm{Cl}^{-}$solution.

The correlation between the average corrosion rate and the crack width $\left(w_{\mathrm{cr}}\right)$ is presented in Figure 7 . For a given concentration of chloride solution, the average corrosion rate can be found increased with the increasing crack width. In general, the trends between the corrosion rate and the crack width shown in Figure 7 can be expressed as follows:

$$
i_{\text {corr }}=c w_{\text {cr }}{ }^{d}\left[\mu \mathrm{A} / \mathrm{cm}^{2}\right] \text {, }
$$

TABLE 3: The coefficients $a$ and $b$ for variable crack width in (5).

\begin{tabular}{lcc}
\hline Crack width & $a$ & $b$ \\
\hline Uncracked & 0.02 & 26.49 \\
$0.2 \mathrm{~mm}$ & 0.12 & 25.47 \\
$0.3 \mathrm{~mm}$ & 0.15 & 25.28 \\
$0.4 \mathrm{~mm}$ & 0.17 & 24.71 \\
$0.5 \mathrm{~mm}$ & 0.22 & 23.13 \\
\hline
\end{tabular}

where $c\left(\mu \mathrm{A} / \mathrm{cm}^{2}\right)$ and $d(-)$, presented in Table 4 , are coefficients whose values are dependent on concentration of chloride solution. For uncracked specimens, the value of $w_{\mathrm{cr}}$ is equal to zero; thus the data for uncracked specimens is not shown in Figure 7. 


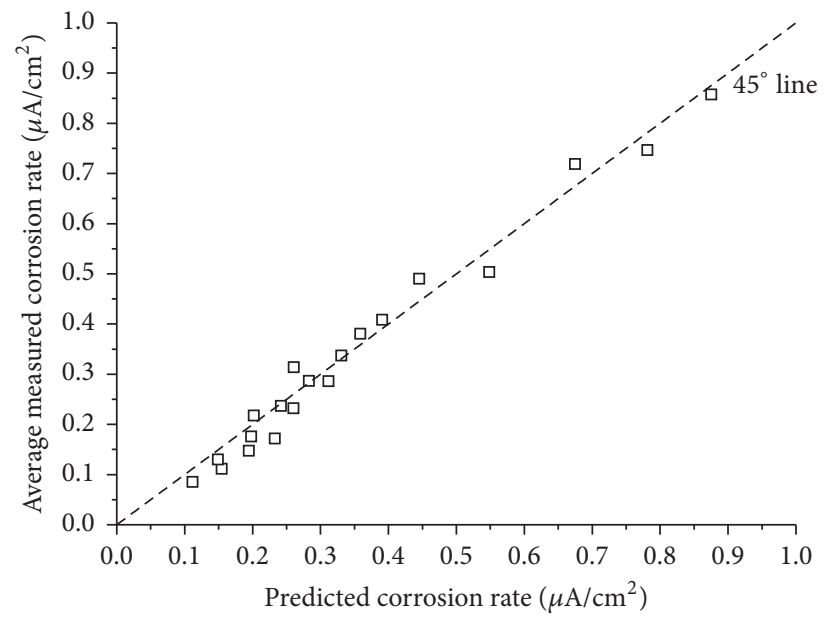

FIGURE 8: Predicted versus actual measured corrosion rates of cracked specimens.

TABLE 4: The coefficients $c$ and $d$ for variable concentration of chloride solution in (6).

\begin{tabular}{lcc}
\hline Concentration of chloride solution & $c$ & $d$ \\
\hline $0.6 \%$ & 0.30 & 0.79 \\
$1.2 \%$ & 0.53 & 0.72 \\
$2.1 \%$ & 0.58 & 0.68 \\
$3.0 \%$ & 0.68 & 0.53 \\
$6.0 \%$ & 1.24 & 0.52 \\
\hline
\end{tabular}

The general relationships of the corrosion rate with the crack width and concentration of chloride solution have been presented in (5) and (6). For the purpose of developing an empirical prediction model, both the concentration of the chloride solution and the crack width should be incorporated in a single equation to predict the corrosion rate of cracked specimens. When the coefficients $c$ and $d$ in (6) are both incorporated, the effect of crack width and concentration of chloride solution, therefore, (5) and (6) can then be combined in a single equation. It should be noted that the values for $c$ and $d$ can be fit to the data for cracked specimens from Figure 7.

When the values of $c$ and $d$ are plotted against the concentration of chloride solution, the variations of $c$ and $d$ with crack width $\left(w_{\mathrm{cr}}\right)$ can be established, and the resulting fitted equations are as follows:

$$
\begin{aligned}
& c=0.358 e^{20.801 D}, \\
& d=0.294 D^{-0.196} .
\end{aligned}
$$

After the coefficients $c$ and $d$ in (6) were then replaced with those in (7), the resulting empirical prediction model for corrosion rate is given in (8).

$$
i_{\text {corr }}=0.358 e^{20.801 D} w_{\text {cr }}^{0.294 D^{-0.196}}\left[\mu \mathrm{A} / \mathrm{cm}^{2}\right] .
$$

A comparison between the predicted corrosion rate from (8) and the measured average corrosion rate has been conducted in Figure 8. The results in this figure indicate that the predicted corrosion rate is in good agreement with the corresponding measured average corrosion rates.

For illustration purposes, the graphical representations of (8) for various crack widths and concentrations of chloride solution are given in Figures 9 and 10. The value of crack width and concentration of chloride solution are arbitrarily selected to show the general trend of corrosion rate as a function of crack width and concentration of chloride solution. The following general observations can be made from Figures 9 and 10:

(i) The corrosion rate is sensitive to both the crack width and the concentration of chloride solution.

(ii) When the chloride concentration is less than $2.7 \%, w_{\mathrm{cr}}$ could be kept less than $0.05 \mathrm{~mm}$ to limit the corrosion rate less than $0.1 \mu \mathrm{A} / \mathrm{cm}^{2}$. Analogously, for crack of $0.1 \mathrm{~mm}$ and $0.2 \mathrm{~mm}$ width, the chloride concentrations must be less than $1.5 \%$ and $0.9 \%$, respectively, to limit the corrosion rate less than $0.1 \mu \mathrm{A} / \mathrm{cm}^{2}$.

(iii) The critical chloride concentration to limit the corrosion rate less than $0.1 \mu \mathrm{A} / \mathrm{cm}^{2}$ increases with decreasing crack width.

4.3. Open Circuit Corrosion Potential. The trends of the rebar in the development of the open circuit corrosion potential are shown in Figures 11(a)-11(e) for different concentrations of chloride ion solution. In general, the following results can be found with respect to the corrosion potential results:

(i) For a given experiment environment, the corrosion potential became less negative in the following order: uncracked $<0.2 \mathrm{~mm}$ crack $<0.3 \mathrm{~mm}$ crack $<0.4 \mathrm{~mm}$ crack $<0.5 \mathrm{~mm}$ crack.

(ii) It should be noted that the addition of chloride ions produced a shift of $E_{\text {corr }}$ towards lower value because, in the presence of chloride ions, a passivity breakdown occurred, and the potential decreased with increasing chloride concentration.

The relationship between the corrosion potential and the corrosion rate is shown in Figure 12. The Figure shows that the corrosion potential was well correlated with the corrosion 


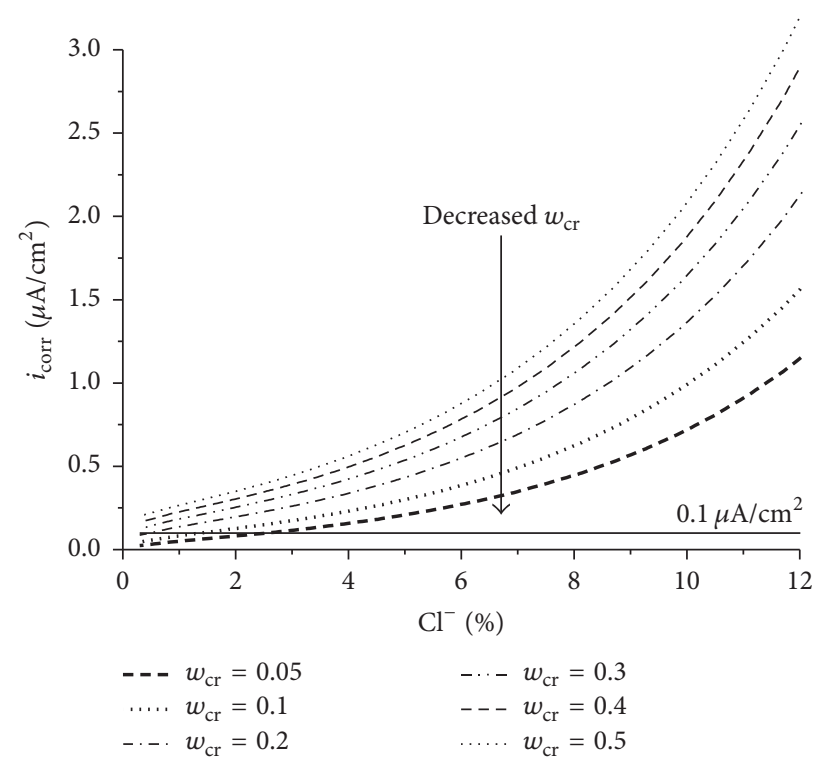

FIGURE 9: Variation of corrosion rate with the concentration of the $\mathrm{Cl}^{-}$solution.

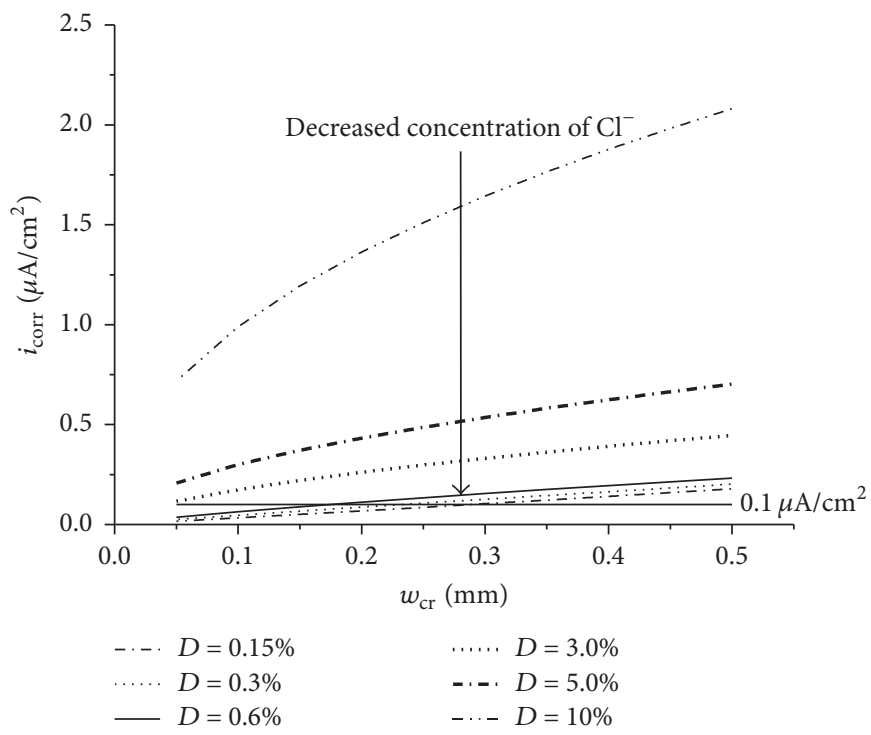

FIGURE 10: Variation of corrosion rate with crack width.

rate; that is, higher corrosion rates corresponded to more negative corrosion potentials.

\section{Conclusions}

Concrete cover of $\mathrm{RC}$ element provides protection to rebar from corrosion. It is widely recognized that uncracked concrete performed significantly better than cracked concrete components when RC elements are subjected to an ion-rich environment. A series of experimental investigations have been carried out on cracked concrete prisms in the study to evaluate the influences of both crack width and concentration of chloride solution on corrosion performance. Based on the experimental results, an empirical prediction model for chloride-induced corrosion rate of cracked RC elements was proposed. Furthermore, the following conclusions can be drawn:

(1) The appearance of cracks in concrete significantly increased the corrosion rate, and, for a given exposure environment, the corrosion rate increases with increasing crack width.

(2) For a given crack width, the addition of chloride ions noticeably increased the corrosion rate.

(3) An empirical model which incorporated the influence of crack width and the concentration of chloride solution was proposed to predict the corrosion rate. This model can specify the maximum allowable crack width and chloride concentration to achieve a corrosion rate below a desired value.

(4) For cracked reinforced concrete, both the crack width and chloride concentration should be limited. With 


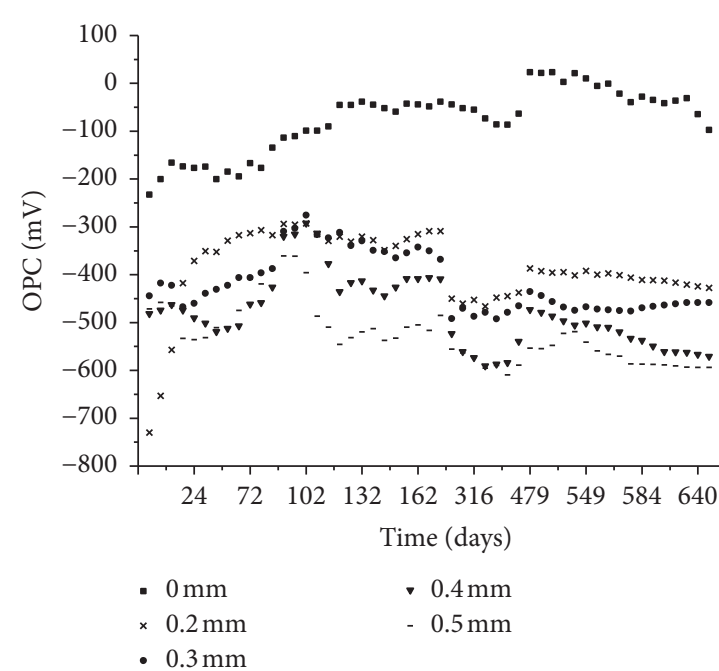

(a) $0.6 \%$ concentration of $\mathrm{Cl}^{-}$

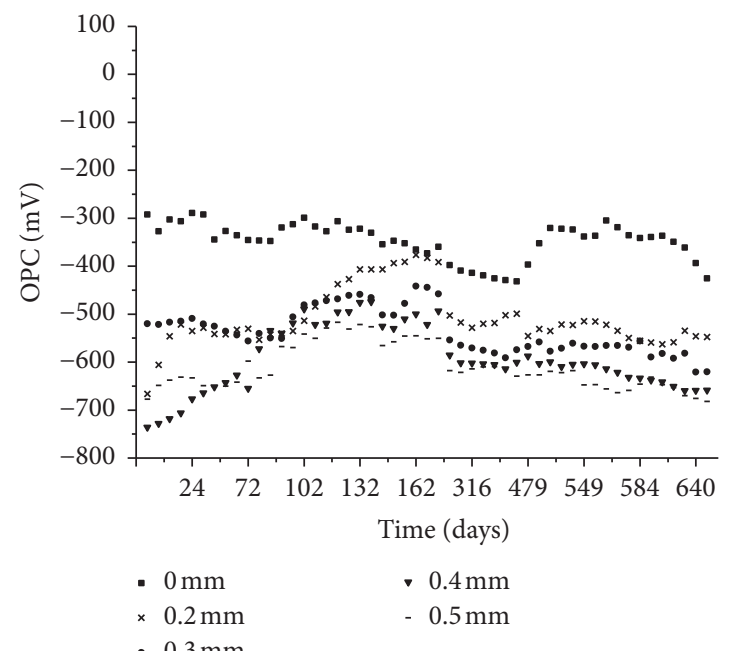

(c) $2.1 \%$ concentration of $\mathrm{Cl}^{-}$

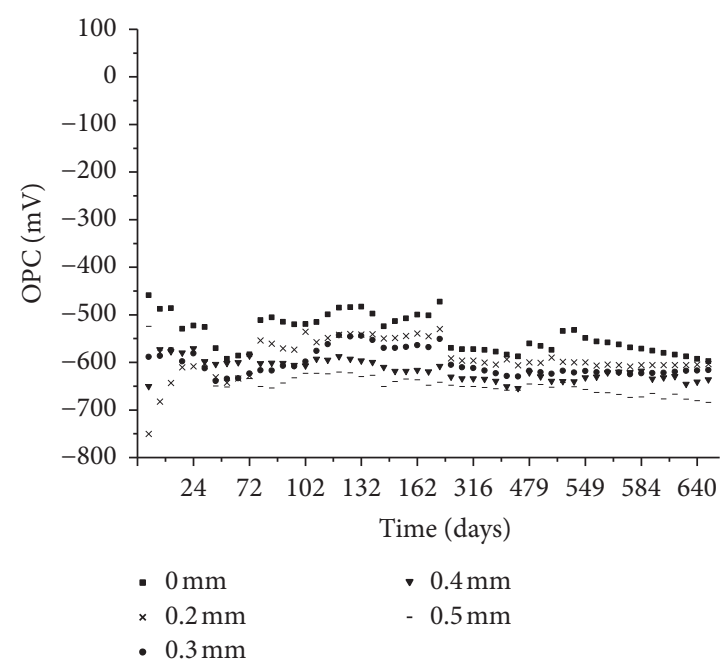

(e) $6.0 \%$ concentration of $\mathrm{Cl}^{-}$

FIGURE 11: Time-development of the open circuit corrosion potential. 


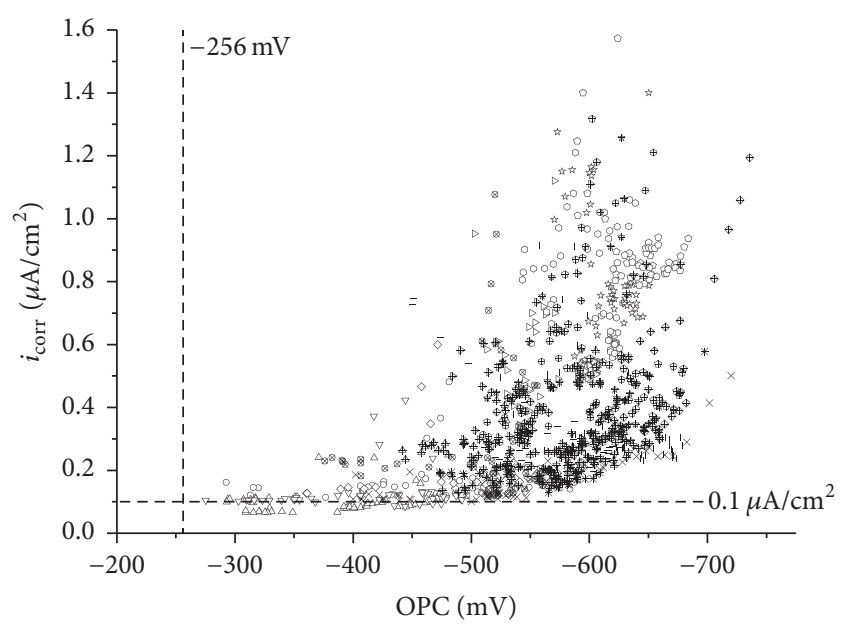

FIGURE 12: Relationship between the corrosion rate and the open circuit corrosion potential.

increasing values of critical chloride concentration, the corresponding crack width to limit the corrosion rate to less than $0.1 \mu \mathrm{A} / \mathrm{cm}^{2}$ limit decreases.

\section{Conflicts of Interest}

The authors declare that they have no conflicts of interest.

\section{Acknowledgments}

This work was supported by the National Basic Research Program of China (973 Program: 2011CB013800), the Major Program of Natural Science Foundation of the Jiangsu Higher Education Institutions of China (14KJA560001), and the General University Postgraduate Research and Creative Project of Jiangsu Province (Grant no. CXZZ13_0440).

\section{References}

[1] P. Sandberg, L. Tang, and A. Andersen, "Recurrent studies of chloride ingress in uncracked marine concrete at various exposure times and elevations," Cement and Concrete Research, vol. 28, no. 10, pp. 1489-1503, 1998.

[2] C. Barris, L. Torres, I. Vilanova, C. Miàs, and M. Llorens, "Experimental study on crack width and crack spacing for Glass-FRP reinforced concrete beams," Engineering Structures, vol. 131, pp. 231-242, 2017.

[3] C. In, K. Arne, J. Kim, K. E. Kurtis, and L. J. Jacobs, "Estimation of crack depth in concrete using diffuse ultrasound: validation in cracked concrete beams," Journal of Nondestructive Evaluation, vol. 36, no. 1, 2017.

[4] O. S. B. Al-Amoudi and M. Maslehuddin, "The effect of chloride and sulfate ions on reinforcement corrosion," Cement and Concrete Research, vol. 23, no. 1, pp. 139-146, 1993.

[5] P. Gu, J. J. Beaudoin, M.-H. Zhang, and V. M. Malhotra, "Performance of reinforcing steel in concrete containing silica fume and blast-furnace slag ponded with sodium chloride solution," ACI Structural Journal, vol. 97, no. 3, pp. 254-262, 2000 .
[6] T. U. Mohammed, H. Hamada, and T. Yamaji, "Concrete after 30 years of exposure-Part II: chloride ingress and corrosion of steel bars," ACI Materials Journal, vol. 101, no. 1, pp. 13-18, 2004.

[7] Y. Ohno, S. Praparntanatorn, and K. Suzuki, "Influence of cracking and water cement ratio on macrocell corrosion of steel in concrete," in Corrosion of Reinforcement in Concrete Construction, The Royal Society of Chemistry, Cambridge, UK, 1996.

[8] C. Arya and F. K. Ofori-Darko, "Influence of crack frequency on reinforcement corrosion in concrete," Cement and Concrete Research, vol. 26, no. 3, pp. 345-353, 1996.

[9] B. Šavija and E. Schlangen, "Chloride ingress in cracked concrete-a literature review," in Proceedings of 4th International RILEM PhD Workshop, pp. 133-142, Madrid, Spain, 2012.

[10] C. Q. Li, "Corrosion initiation of reinforcing steel in concrete under natural salt spray and service loading-results and analysis," ACI Structural Journal, vol. 97, no. 6, pp. 690-697, 2000.

[11] C. Q. Li, "Initiation of chloride-induced reinforcement corrosion in concrete structural members-experimentation," $A C I$ Structural Journal, vol. 98, no. 4, pp. 502-510, 2001.

[12] P. Schiessl and M. Raupach, "Laboratory studies and calculations on the influence of crack width on chloride-induced corrosion of steel in concrete," ACI Materials Journal, vol. 94, no. 1, pp. 56-62, 1997.

[13] P. Montes, T. W. Bremner, and D. H. Lister, "Influence of calcium nitrite inhibitor and crack width on corrosion of steel in high performance concrete subjected to a simulated marine environment," Cement and Concrete Composites, vol. 26, no. 3, pp. 243-253, 2004.

[14] Y. Ohno, K. Suzuki, and S. Praparntanatorn, "Macrocell corrosion of steel in cracked concrete," in Proceedings of the International Conference on Corrosion and Corrosion Protection of Steel in Concrete, pp. 324-336, Sheffield, UK, 1994.

[15] R. François and G. Arliguie, "Influence of service cracking on reinforcement steel corrosion," Journal of Materials in Civil Engineering, vol. 10, no. 1, pp. 14-20, 1998.

[16] T. Vidal, A. Castel, and R. François, "Corrosion process and structural performance of a 17 year old reinforced concrete beam stored in chloride environment," Cement and Concrete Research, vol. 37, no. 11, pp. 1551-1561, 2007.

[17] S. J. Jaffer and C. M. Hansson, "The influence of cracks on chloride-induced corrosion of steel in ordinary Portland cement and high performance concretes subjected to different loading conditions," Corrosion Science, vol. 50, no. 12, pp. 3343$3355,2008$.

[18] I. L. Kondratova, P. Montes, and T. W. Bremner, "Natural marine exposure results for reinforced concrete slabs with corrosion inhibitors," Cement and Concrete Composites, vol. 25, no. 4-5, pp. 483-490, 2003.

[19] R. Bandy, "The simultaneous determination of tafel constants and corrosion rate-a new method," Corrosion Science, vol. 20, no. 8-9, pp. 1017-1028, 1980. 

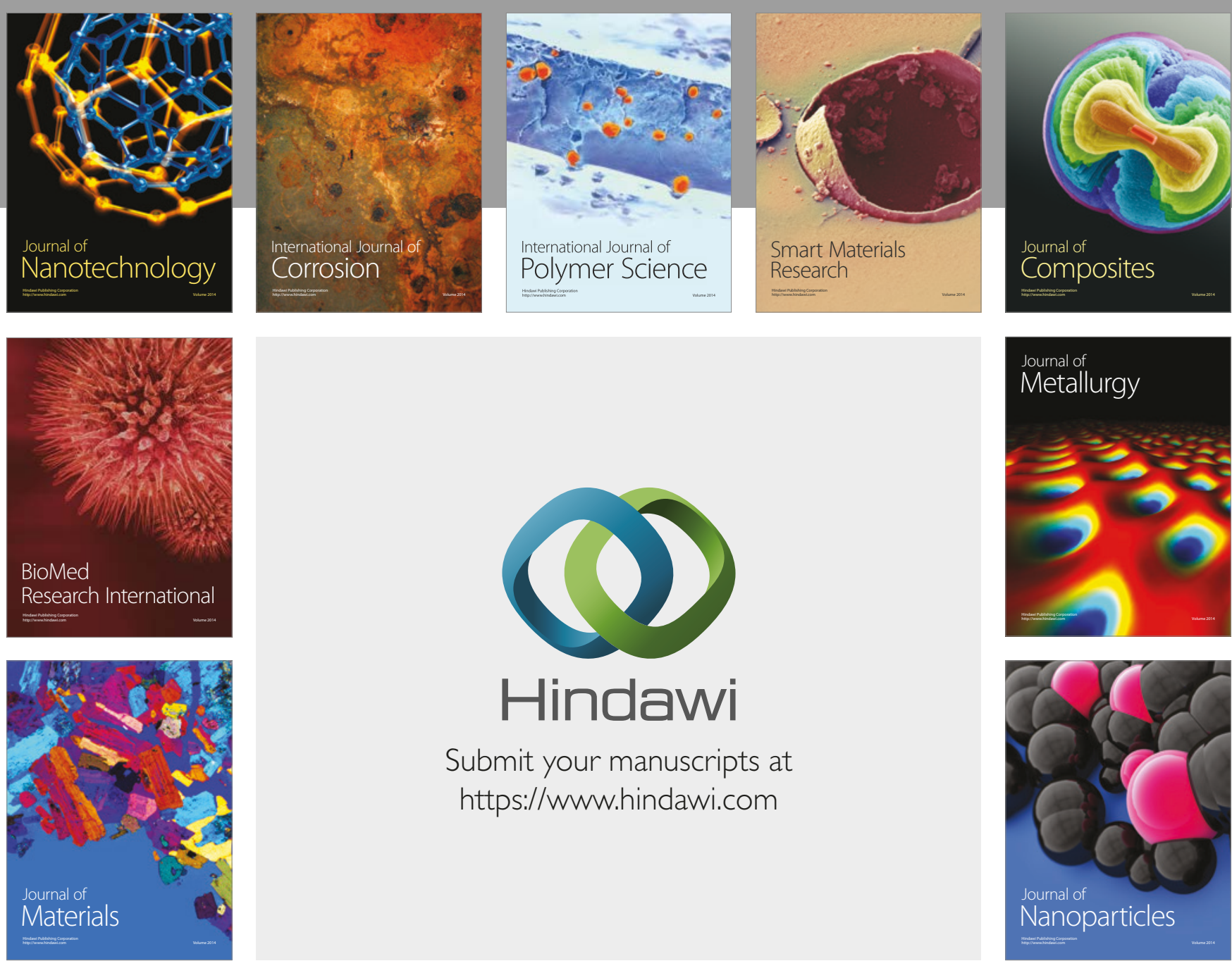

\section{Hindawi}

Submit your manuscripts at

https://www.hindawi.com
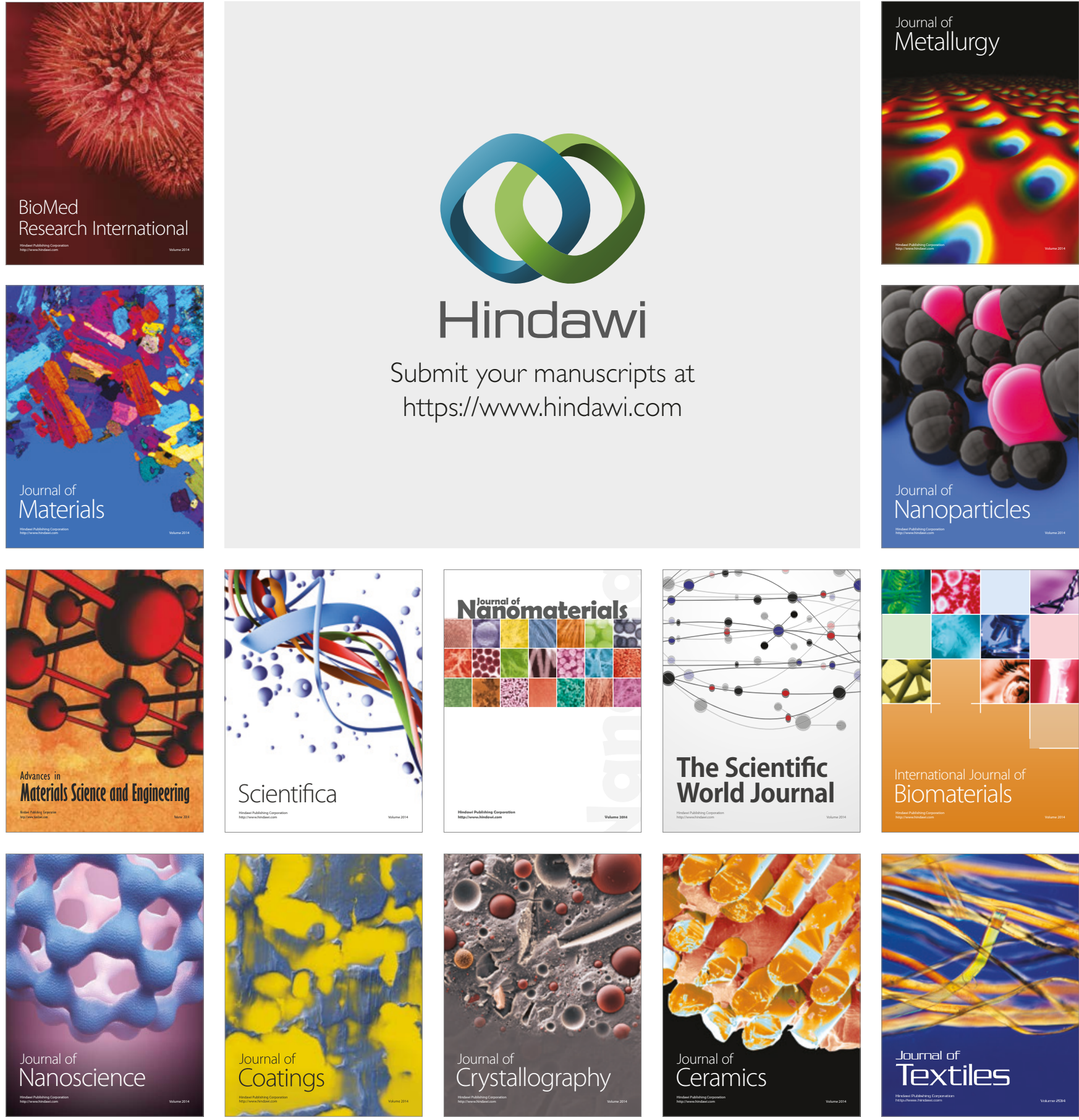

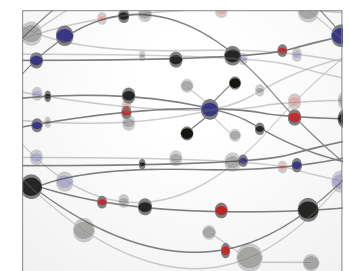

The Scientific World Journal
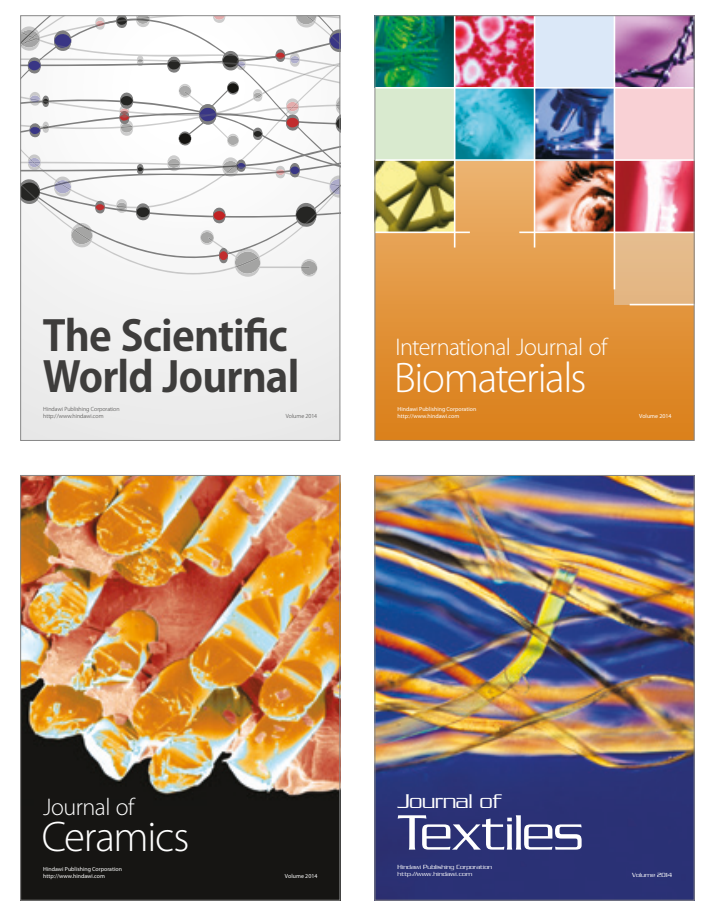